\title{
CORRESPONDENCE
}

Rugby football injuries to the cervical spine

J E Carvell, FrCs, and others.

Can aphasic patients with stroke do without speech therapists?

D T Wade, MRCP.

Bromocriptine induced psychosis in acromegaly

A W Procter, $M B$, and others; I F Pye, $M D$, and $R$ Abbott, MRCP................

Choosing treatment for metastatic breast

cancer

$\mathrm{K}$ W James, FRCR, and others; $\mathrm{R}$ Stuart-

Harris, MRCP, and others.......... 51

Mastectomy and its consequences

P Michaclson, AIST.

Multimodal treatment in operable breast cancer

C Trask, $M B$, and R L Souhami, FRCP. . .

Recurrent hyperinfestation with

Strongyloides stercoralis in a renal

allograft recipient

A Bush, MrCP, and R Gabriel, FrCP; B J Gatus, MRCP; J G Thornton, MB

Cryptic stage of sleeping sickness trypanosome developing in choroid plexus epithelial cells

Angela J Barnicoat, BSC, and W G van't Hoff, BSC; A A Poltera, MD

Estimation of urine specific gravity and osmolality using a simple reagent strip O J Hensey, MRCPI, and R W I Cooke, MD . . . 53

Admission after mild head injury:

benefits and costs

J Y Thomson, MrCGP, and P Simms, FrCs; J J Jones, MFCM.

Letters to a young doctor

$M$ D Vickers, FFARCS; Margaret L Heath, FFARCS; D M Bowers, MB..

A new approach to the elderly

Lindsay Burley, MRCGP; N D Pandita-

Gunawardena; G E Langley, FrCPSYCH. . . . 54

Popular marathons: forecasting casualties

G K Terpstra, PHD .
Magnesium deficiency and diuretics L B Tan, MB.

49 Alternative medicine: cost and subjective benefit in rheumatoid arthritis

I H J Bourne, FRCGP; P E Baldry, FRCP

50 Death from asthma in two regions of England R P Beekman, MD .

Peer review weighed in the balance J G Howells, FRCPSYCH; R Mahler, FRCP ... . 56

High serum vitamin $B_{12}$ binding capacity as a marker of the fibrolamellar variant of hepatocellular carcinoma K J Sheppard, FIMLS, and others.

51 Glomerular filtration rate in schoolgirls with covert bacteriuria $\mathrm{J}$ Guillet, MD, and others

51 Better science not less science A G Johnson, FRCS, and J M Simms, FrCs.

Assessment of Fecatest and Haemoccult for faecal occult blood testing

F I Lee, FRCP, and F T Costello, MRCP.

52 Dietary advice

D Craddock, FRCGP........................

Does control of risk factors

P Carson, FRCP, and Rosalind Phillips, MB . . 58

52 Laboratory acquired shigellosis J V Dadswell, FRCPATH. . .

Antenatal screening by measurement of symphysis-fundus height

I Kennedy, FRCSED.

Notifications of tuberculosis in England and Wales

W Fox, FRCP, and $\mathrm{K} M$ Citron, FRCP.

Retrolental fibroplasia and mental

handicap

H G Kinnell, MRCPSYCH. .

Intensive attention improves glycaemic control in insulin dependent diabetes

without further advantage from home

blood glucose monitoring

R H Harrad, MRCP, and others.
Outbreak of chickenpox from a patient with immunosuppressed herpes zoster in hospital

B E Juel-Jensen, FRCP . . . . . . . . . . . 60

56 Future of cottage hospitals

R M Emrys-Roberts, FRCGP . . . . . . . . 60

Hours of work of junior hospital doctors

K D Vellacott, FRCS; W T Berrill, MRCP . . . . 60

Admission of children to general practitioner hospitals

I McColl, FRCS, and A O Russell, MRCGP . . . 60

BMA subscription rates

Diana Kiernan, MB..............

57 Medical unemployment

J M Reid, FRCP.

Cot deaths and medical communication

J L Emery, frcpath. ............. 6

Correction: Near miss cot deaths (Wright) 61

57 Points Renal artery thrombosis caused by antihypertensive treatment (L E Ramsay); Small causes may have great effects ( G C R Morris); Chemoprophylaxis of malaria in Africa (D B A Hutchinson and J A Farquhar); Introduction of 100 unit insulin (K A Harden); Appropriate use of local resources (M McCarthy); Kidney pseudotumour diagnosed by emission computed tomography (Elisabeth $\mathrm{M}$ Watkin); Is this a record ? (C D $M$ Bone); Poverty and ideology (A ScottSamuel); A regimen of low dose aspirin (W J O'Connell); Origin of the medical symbol of the rod and serpents (D A Dyson); Portrait of a social reformer (R Hughes Parry) 62 Early detection of glaucoma (J P F Lloyd); Confidentiality of patients' records (C W D Phillips); Data for management: the Körner Report (M Black and Jean Harris); Little people of America (D P Davies); Aminophylline toxicity in the elderly ( $T$ G K Mant and others); A diploma in clinical medicine (N H Gardezi); Lost in words (D Crowther); Cost of reprints (Sir Ian Fraser); Unnecessary examinations (J Brown) ................. 63

Some letters in this week's issue contain references in which the titles of articles are given; in others the titles are missing because the letters were prepared some time ago. From 8 fanuary we shall print all references to letters in full, and authors should therefore provide the titles of articles and chapters in their references. Letters submitted with incomplete references may be returned for correction.

\section{Rugby football injuries to the cervical spine}

SIR,-Public attention has again been drawn to the incidence of spinal injury during a game of rugby football as a result of the injury sustained by the medical student from Guy's Hospital (2 October, p 984). The cervical spine is particularly at risk both in open play, during a tackle, and in relatively static play - that is, scrummaging or a maul. ${ }^{1-3}$ Although injuries to the cervical spine are reported to be uncommon, their true incidence is not recorded either in this country or world wide, and there is evidence that the numbers are increasing. ${ }^{34}$

In the last three weeks three teenage schoolboy have presented to the accident service with significant injuries of the cervical spine incurred while playing rugby. All were hyperflexion injuries, one being sustained on the collapse of set scrum and two during the formation of a maul when the players landed badly with the ball. Two of the injuries were associated with fractures. Two boys had significant flaccid paresis of the upper limbs: one boy had bilateral paresis as- sociated with a fracture of $\mathrm{C} 5$ and $\mathrm{C} 7$, and in the other there was no associated fracture. The third boy had a crush fracture of T1 without neurological problems. All the fractures were stable as confirmed by flexion-extension films, using muscle relaxants, tomography, and a computed tomogram as necessary. Two of the patients were mobilised in collars, and the third, with fractures of $\mathrm{C} 5$ and $\mathrm{C} 7$, was initially treated by halotraction and mobilised in a halo body vest.

In 1979 the Medical Officers of Schools Association highlighted the increasing incidence of injuries to the cervical spine in schoolboys playing rugby. ${ }^{5}$ The figures published indicated that, although only five cases of cervical cord injury, two fatal and three resulting in permanent tetraplegia, had been reported in schoolboys in the 27 years between 1942 and 1968, the numbers had risen to 12 in the six years from 1973 to 1978 Sixteen injuries of the cervical spine, including fractures, fracture dislocations, subluxation, or severe ligamentous damage without permanent neurological deficit, were recorded from 1971 to 1978. All were sustained during a set scrum collapse, a ruck, or a maul. A New Zealand survey of cervical injury in rugby football over the five years from 1973-8 found 54 cases of injury, five of which were fatal. ${ }^{7}$ The evidence from this review suggested that the injuries to younger players were likely to be more serious. One quarter of the players were under 17 at the time of the accident.

We are particularly concerned about the incidence of this serious injury in teenagers. Adolescent boys, with immature growing cervical spines, are at considerable risk during scrummaging. Unlike first class rugby players who specialise in certain aspects of forward play because their mature physique has enabled them to compete with similarly built individuals with relative safety, schoolboys are not always matched with their.competitors in either size or technique. Schoolmasters who are responsible for the welfare of these children must now be aware of the all too frequent tragic consequences of scrummage play at this level, and the safety of the individual boy is paramount in every aspect of the game.

Schoolboys, who may not have any choice but to play rugby, cannot be expected to appreciate that a "do or die" attitude to an apparently 
important match is unjustified when they are led to believe that the team is more important than the individual. These attitudes need urgent reappraisal. In May 1979 the Medical Officers of Schools Association issued a series of guidelines in an attempt to prevent or reduce the number of injuries. ${ }^{8}$ In response the Rugby Football Union began collecting information about the number of neck injuries sustained in school matches with a view to publishing a definitive statement. ${ }^{6}$ An accurate and definitive statement is long overdue on what has been a recognised problem for som time. The registration of all such injuries by schools and rugby clubs should be made compulsory and rigorously maintained by the Rugby Football Union or a similar responsible central body. This should include a description of the incident; the player's age, weight, and height; and, after consultation with an orthopaedic surgeon, details of the injury sustained.

Meanwhile, the onus is on players to refrain from foul play and illegal tactics and on referees to be aware continually of the risks, to control the game, and to penalise the players appropriately. We hope that the spectacle of wheelchair bound, paraplegic, former rugby players being lined up to be greeted by their more fortunate colleagues will not be perpetuated.

JohN E CaRvell D J FULLER ROBERT B DUTHIE JOHN COCKIN

Accident Department,
John Radcliffe Hospital,
Oxford OX3 9DU

Scher A. Rugby injuries to the cervical spinal cord. S Afr Med I 1977;51:473.

Davies JE, Gibson T. Injuries in rugby union
football. Br Med f 1978;ii:1754-61. Williams JPR, McKibbin B. Cervical spine injuries in rugby union football. Br Med $f 1978 ;$;ii:1747.
Hoskins TW. Rugby injuries to the cervical cord. Br.Med F 1978;ii:1783.

Enkins TW. Rugby injuries to the cervical spine in

English schoolboys. Practitioner 1979;223:365.

of neck injuries in schools. Times Education Supple-
of net ment January 1980.

Burry HC, Gowland H. Cervical injury in rugby football-a New Zealand survey. $\mathcal{F}$ Sports Med 1981;15:56.

Silver J, Davies JE, Walkden L, Moffat R, Hoskins T. Report: Annual General Meeting of the Medical
Officers of Schools Association. London: Medical Officers of Schools Association. Lond
Officers of Schools Association, 1979.

\section{Can aphasic patients with stroke do without speech therapists?}

SIR,-Minerva (4 December, p 1663) noted that volunteers could treat aphasic patients as well as speech therapists and then implied that this could save the National Health Service money. This deduction may not be valid.

In David et al's study' ${ }^{1}$ every patient was seen and fully assessed by a trained speech therapist. When the patient was to be treated by a volunteer the volunteer was first seen by the assessing therapist and told the results of the assessment so that the volunteer knew what the patient could and could not do. This explanation to the volunteer of the patient's capability is clearly important. Those patients referred to the study late (more than 12 weeks after their stroke) showed considerable improvement after starting treatment, whether by volunteer or therapist. If one assumes that in the first few months these patients were receiving undirected "therapy" from their relatives and hospital staff then it seems that a professional assessment of the patient's capabilities does help.

I agree, however, that the study does show that after a proper assessment the process of therapy can be carried out by untrained volunteers. This still does not mean that this is a more cost effective way of managing the problem. As the report states the volunteer received "general support" from the therapists. We now use volunteers locally to quite an extent, but it takes up a considerable amount of a therapist's time enrolling the volunteers, arranging and giving talks about stroke, and arranging for suitable matching of volunteers with patients.

I hope that your readers will not conclude from Minerva's comment that speech therapists can be abolished for aphasic patients with stroke. They are still vital to perform proper assessments as well as arranging and helping the volunteers.

Department of Neurology,

\section{Frenchay Hospital,}

David R, Enderby P, Bainton D. Treatment of acquired aphasia: speech therapists and volunteers 45:957-61. I Neurol Neurosurg Psychiatry 1982

\section{Bromocriptine induced psychosis in acromegaly}

SIR,-Dr C M Le Feuvre and others have recently reported a case of a psychotic illness apparently produced by low dose bromocriptine (6 November, p 1315). We would like to describe a case in which this drug apparently caused a relapse in a treated and previously stable schizophrenic patient. We report this case as a cautionary tale should bromocriptine be considered for the treatmen of neuroleptic induced hyperprolactinaemia.

The patient was a 41 year old English woman who was first diagnosed as having paranoid schizophrenia at the age of 26. At that time she showed thought disorder with loosening of association, thought block, and thought insertion She had delusions of control. She experienced auditory hallucinations (two voices commenting on her actions and describing obscene sexual activity) and olfactory hallucinations ("old chloroform, new chloroform, and old oxygen"). These symptoms had been readily controlled with combination of oral and depot neuroleptics, and for two years she had been attending a day hospital for rehabilitation. Her medication then was flupenthixol decanoate (Depixol) $80 \mathrm{mg} /$ week trifluoperazine (Stelazine) $15 \mathrm{mg}$ twice daily, and procyclidine (Kemdarin) $5 \mathrm{mg}$ three times daily.

Her general practitioner referred her to a gynaecologist for removal of her intrauterine device when she was found to have had ammenorrhoea for six months. Physical examination was normal, but investigation showed her to have an increased serum prolactin concentration of $1990 \mathrm{IU} / 1$ (normal range 0-480 IU/1). She was started on bromocriptine at an initial dose of $1.25 \mathrm{mg} /$ day which was increased to $5 \mathrm{mg} /$ day. A few days later she began to experience "screaming voices," which were arguing about a man and commenting on her actions. She described thought insertion-believing that some of her thoughts came from these people-and passivityfeeling that they were trying to make her take an overdose of tablets. Twenty days after starting the bromocriptine she became so distressed that she came to the psychiatric outpatient clinic fearing that she would take an overdose.

She was admitted to hospital. Her antipsychotic treatment was not changed, but the bromocriptine was stopped. After three days the thought disturbances and passivity phenomena had stopped and the voices were less distressing. After eight days these too had ceased, and she was discharged to a day hospital.

Bromocriptine seems to have produced a schizophrenic reaction in this patient and in the patient described by Dr Le Feuvre and others. This is in contrast to previous reports $^{1-3}$ of bromocriptine induced psychoses in which bromocriptine appeared to reduce mania.

A W Procter

R LITTLEWOOD

A H FRY

Department of Psychological Medicine, Guy's Hospital

' Vlissides DN, Gill D, Castelow J. Bromocriptine induced mania? Br Med $\mathcal{F} 1978 ; \mathrm{i}: 510$

Brook NM, Cookson IB. Bromocriptine induced mania. Br Med J 1978; ; :790. ohnson JM. Treated mania exacerbated by bromo-

SIR,-We read with interest the report by Dr C M Le Feuvre and others (6 November, p 1315) of bromocriptine induced psychosis in acromegaly. We have experience of a patient with acromegaly who developed an acute psychotic episode before any treatment began

In February 1980 a 29 year old white woman presented with the clinical features of acromegaly and hyperprolactinaemia. Prolonged galactorrhoea had followed pregnancy seven years previously, and the patient had been amenorrhoeic for two years. There was no previous history of psychotic illness. Shortly before admission to hospital the patient became psychotic; she was deluded, expressed ideas of reference, had visual hallucinations, and described inner voices urging her to harm her children. She was suspicious and refused food and drugs, which she believed to be poisoned. She was treated with chlorpromazine and trifluoperazine, and during the next two weeks her mental state improved. Pituitary function tests showed increased concentrations of basal growth hormone (>100 IU/1) and prolactin (1017 IU/1) (upper limit of normal for growth hormone = $30 \mathrm{IU} / 1$; prolactin $-360 \mathrm{IU} / 1$ ). Neuroradiological investigations confirmed the presence of a pituitary tumour with suprasellar extension.

Treatment with bromocriptine was started up to a maximum dose of $10 \mathrm{mg}$ daily, and over the next month neuroleptic treatment was withdrawn without further psychiatric disturbance. In June 1980 the pituitary adenoma was removed at craniotomy, followed by postoperative radiotherapy. Six months after the operation her basal growth hormone concentration remained raised (at $226 \mathrm{IU} / \mathrm{l}$ ), and bromocriptine treatment was restarted. With this treatment menstruation is normal, and the patient is now well.

Although apathy, lack of initiative, and mood lability have been described in acromegaly in addition to irritability and depression, acute psychosis is a rare complication. In common with the patient described by Le Feuvre and others, our patient had substantial hyperprolactinaemia although she developed psychotic symptoms before treatment with bromocriptine was started. We can only speculate about the underlying mechanism which leads to psychosis in acromegaly. Psychosis can occur in other endocrine disorders such as Cushing's syndrome and hypothyroidism, and in acromegaly these manifestations may be a direct result of growth hormone excess. Alternatively, dopaminergic function in the mesolimbic pathways could be disturbed since the presence of hyperprolactinaemia reflects altered tuberoinfundibular dopamine activity, and functional connections may exist between 